Research Article

\title{
The Vibration Characteristics of Ground of Rock Blasting in Silt-Rock Strata
}

\author{
Tao Yin $\mathbb{D}^{1},{ }^{1}$ Chuanbo Zhou $\mathbb{D}^{2},{ }^{2}$ Changqing Zheng $\mathbb{D}^{\circ},{ }^{3}$ Jugen Fu $\mathbb{D}^{1},{ }^{1}$ and Ziru Guo $\mathbb{D}^{4}$ \\ ${ }^{1}$ School of Civil Engineering and Architecture, Anhui University of Science and Technology, No. 168 Taifeng Street, \\ Huainan 232001, Anhui, China \\ ${ }^{2}$ Faculty of Engineering, China University of Geosciences, No. 388 Lumo Road, Wuhan 430074, Hubei, China \\ ${ }^{3}$ Zhuhai Baopoxin Research \& Development Co., Ltd, No. 2099 Fenghuang North Road, Zhuhai 519099, Guangdong, China \\ ${ }^{4}$ School of Chemical Engineering, Anhui University of Science and Technology, No. 168 Taifeng Street, Huainan 232001, \\ Anhui, China
}

Correspondence should be addressed to Tao Yin; taoyin@aust.edu.cn

Received 6 May 2021; Revised 6 October 2021; Accepted 6 November 2021; Published 30 November 2021

Academic Editor: Vasudevan Rajamohan

Copyright ( 2021 Tao Yin et al. This is an open access article distributed under the Creative Commons Attribution License, which permits unrestricted use, distribution, and reproduction in any medium, provided the original work is properly cited.

\begin{abstract}
As the shield section passes through the silt-rock strata, the rock stratum of the tunnel section has to be blasted into blocks in advance, and the diameter of the blocks should be less than $30 \mathrm{~cm}$ after breaking, and then, the blocks could smoothly enter the soil cabin through the opening of the tunnel boring machine (TBM) cutter head and finally be discharged through the screw machine. The geology of rock blasting in silt-rock strata is complex, and the vibrations caused by blasting threaten the safety of buildings around the blasting area. According to the measured data of blasting vibrations at the sites, the waveform duration of vibration acceleration and the distribution characteristics of dominant frequency of vibration velocity were analyzed, the energy characteristics of vibration velocity were researched by wavelet analysis, and the attenuation laws of vibration velocity were studied by dimensional analysis (DA). The dominant frequency bands of vibration energy of ground are in the range of $0-15.625 \mathrm{~Hz}$, and the distribution characteristics of frequency bands of vibration energy in different directions of the ground are similar to each other, but the energy magnitude is different from each other. The research results could provide a reference for the safe blasting distance of buildings under similar geological conditions.
\end{abstract}

\section{Introduction}

With the fast economic growth in China, the demand for urban underground space engineering is growing rapidly. By 2020, there have been 33 cities with 177 subway lines in China [1]. In the construction of metro tunnel shield method, the silt-rock strata often encounter in the range of section, such as Shenzhen Metro Line 11 [2], Xiamen Metro Line 2 [3], Shenzhen Metro Line 5 [4], and Fuzhou Metro Line 1 [5], and when the shield machine passes through the silt-rock strata, the rock stratum in the lower part is not easy to break, while the silt stratum in the upper part is easy to enter into the soil cabin, especially the silt stratum, which is rich in groundwater. Once the soil pressure in the sealed soil cabin is unbalanced, it is easy to cause soil loss, large settlement, and collapse accident. Many scientists had researched to solve this problem [1-5]. They concluded that when the rock stratum of the tunnel section was blasted into blocks in advance, and the diameter of the blocks should be less than $30 \mathrm{~cm}$ after breaking, then the blocks could smoothly enter the soil cabin through the opening of the TBM cutter head and finally be discharged through the screw machine.

There are many studies about blasting in rock, soil, air, and water, but few researches about rock blasting in the siltrock strata. The removing and replacing silt layer by explosion has been investigated comprehensively in China. For example, Yang et al. [6] studied the propagation laws of blast waves in silt, which were similar to that in water and satisfied the geometrical similarity law. $\mathrm{Li}$ et al. [7] researched the 
vibration effect of removing and replacing silt layer by explosion in deep silt and obtained that the high tide level could reduce the negative effect of blasting vibrations and the low tide level had a positive impact on the peak velocity of blasting vibrations. $\mathrm{Xu}$ et al. [8] applied the regression analysis by Sadovski's formula and obtained the attenuation laws of peak particle velocity (PPV) with distance in the removing and replacing silt layer by explosion. W. Wei [9] adopted many blasting tests in soft marine silt clay at the sites of Ningbo and obtained the time history of blast wave pressure, excess pore water pressure, and temperature of soft soil under different buried depths of explosive. Some foreign researchers had conducted a lot of experiments to compact soil by blasting. C. WA et al. [10] studied that the blasting vibrations could cause the liquefaction of saturated soil; however, the liquefaction caused by blasting load was different from that caused by seismic load. Mikulyak [11] modeled the blasting by computer in geological conditions of soft soil and investigated the formation characteristics of two kinds of spherical cavities by different blasting schemes.

Some scientists studied the blasting vibration waveform by wavelet analysis. D. Huang [12] analyzed the time-frequency characteristics of measured vibration signal of the mountain tunnel by the Fourier transform and the wavelet packet transform. Y. Yang [13] studied the blasting vibration signals of different elevations and explosion distances of an open-pit mine based on the wavelet packet theory. Józef Pyra [14] used various methods of time and frequency to analyze the vibration induced by blasting works carried out in open-cast mines.

Other scientists have studied the propagation law of blasting vibration by DA. M. Khandelwal [15] performed a DA technique to propose a new formula for the prediction of the PPV. Dehghani [16] evaluated and calculated the blastinduced ground vibration by artificial neural networks and DA techniques. Olarewaju [17] used the finite element method to study the dynamic dimensionless behaviors of underground pipes due to blast loads.

The analysis of vibration characteristics of ground of rock blasting in silt-rock strata by wavelet analysis and DA has been less reported at present. This study relied on the rock blasting engineering in silt-rock strata in the shield section of Zhuhai Metro, the waveform and the distribution characteristics of frequency of blasting vibrations were analyzed, the energy characteristics of blasting vibrations in different frequency bands were studied by wavelet analysis, and the attenuation laws of vibration velocity were fitted by DA. The dominant frequency bands of vibration energy of ground are in the range of $0-15.625 \mathrm{~Hz}$, and the distribution characteristics of frequency bands of vibration energy in different directions of the ground are similar to each other, but the energy magnitude is different from each other. The research results could provide a reference for the safe blasting distance of buildings under similar geological conditions.

\section{Project Overview}

The shield section between Hengqinbei Railway Station and Hengqin Railway Station of Zhuhai-Zhuhai Airport Intercity Railway is located in the Economic Development Zone of Hengqin Island, Zhuhai City, as shown in Figure 1. It runs along the coastline of South China Sea, with a total length of $2.656 \mathrm{~km}$, all of which is constructed by the shield method.

As the shield section passes through the silt-rock strata, the rock stratum of the tunnel section has to be blasted into blocks in advance, and the diameter of the blocks should be less than $30 \mathrm{~cm}$ after breaking, and then, the blocks could smoothly enter the soil cabin through the opening of the cutter head and finally be discharged through the screw machine. The diagram of charging on field is shown in Figure 2. The rock cores before blasting and after blasting are shown in Figure 3.

The blasting area is located in the artificial reclamation area, and there are three strata from the ground surface to the subway tunnel. (1) The first stratum is artificial fill. It is yellowish-brown, slightly wet, mainly in saturated loose state, and slightly compacted, and the artificial fill is mostly pavement concrete with a thickness of $20-35 \mathrm{~cm}$, and the layer thickness is in the range of $0.30-15.10 \mathrm{~m}$, and the average layer thickness is $2.82 \mathrm{~m}$. (2) The second stratum is silt. It is from gray to dark gray, saturated, and in flow plastic state, with uniform and fine soil, locally enriching with shell debris and sand. The layer thickness is in the range of $0.50-30.30 \mathrm{~m}$. (3) The third stratum is rock. It is weakly weathered granite. It is brown-yellow, gray-brown, graywhite, and other colors, medium-coarse grain structure, and massive structure. The joint fissures are developed relatively. The rock quality is hard. The buried depth of the layer fluctuates greatly, and the distribution is discontinuous. The physical and mechanical parameters of artificial fill, silt, and rock are listed in Tables 1 and 2, respectively.

The length of the blasting area is $960 \mathrm{~cm}$, and the width of the blasting area is $160 \mathrm{~cm}$. The casing drilling method is used for drilling blastholes, and the PVC casing with a diameter of $7.5 \mathrm{~cm}$ is installed immediately after the blasthole is formed for protecting the blasthole wall. The spacing and row spacing of blastholes are both $80 \mathrm{~cm}$, the diameter of blastholes is $14.6 \mathrm{~cm}$, and the depth of blastholes is $3400 \mathrm{~cm}$. Three rows of blastholes are detonated each time, 13 blastholes are arranged in a row, and the millisecond blasting network in the blasthole is adopted. The millisecond sections of three rows of blastholes are 6, 7, and 8 in turn, and the delay time is $50 \mathrm{~ms}$. The layouts of blastholes are shown in Figure 4.

After drilling the blastholes, the blastholes are filled with underground water immediately, and the blastholes are water coupling charge. The diameter of the explosive roll is $6 \mathrm{~cm}$, and the density of the explosive is $1061 \mathrm{~kg} / \mathrm{m}^{3}$. The continuous charge is adopted, the charge length is the depth of the rock at the tunnel section, and the thickness of the rock to be blasted is in the range of 1-8 $\mathrm{m}$. The blastholes are stemmed with gravels of $1-1.5 \mathrm{~cm}$ diameter, and the stemming length is $1000 \mathrm{~cm}$.

\section{Test Points of Blasting Vibrations}

The TC-4850 self-recording instrument (developed and manufactured by Zhongke (Chengdu) Instruments Company Limited) was used as the blasting vibrations measuring 


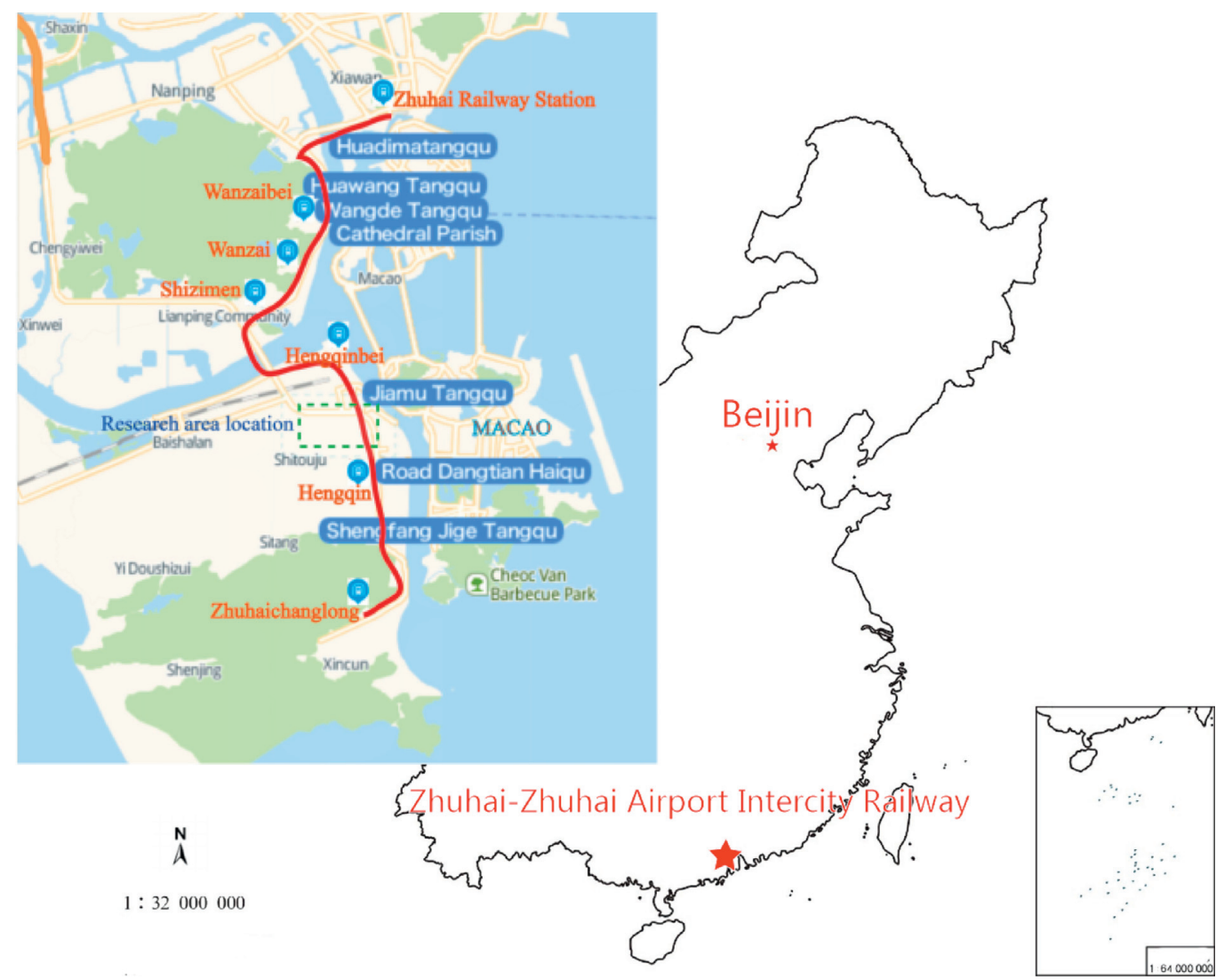

Figure 1: Zhuhai-Zhuhai Airport Intercity Railway.

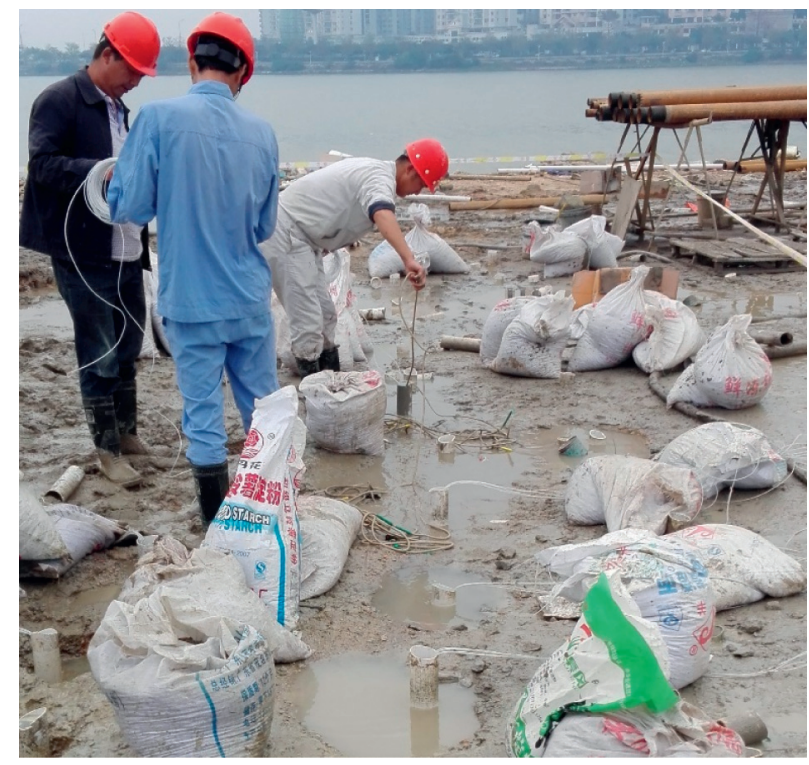

FIGURE 2: Diagram of charging on field.

instrument during the blasting, each instrument had three channels, and it could be collected in parallel. The arrangement of blasting vibration meters is shown in Figure 5.
Three acceleration measuring points and six velocity measuring points were arranged in total. The measuring points were arranged along the ray with the explosion source 


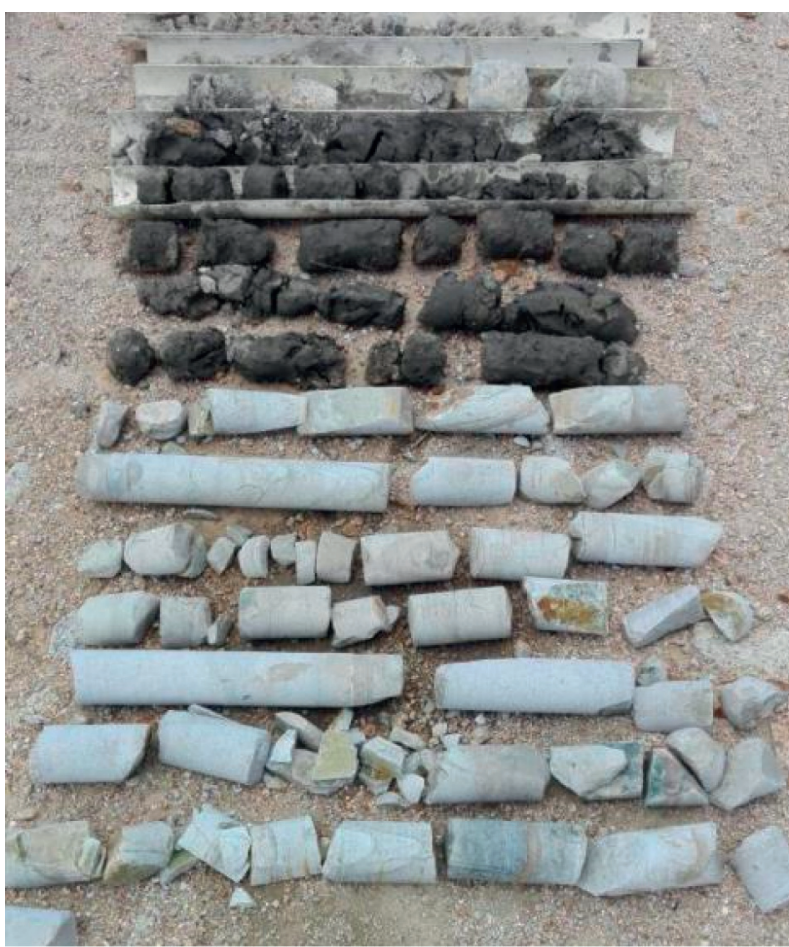

(a)

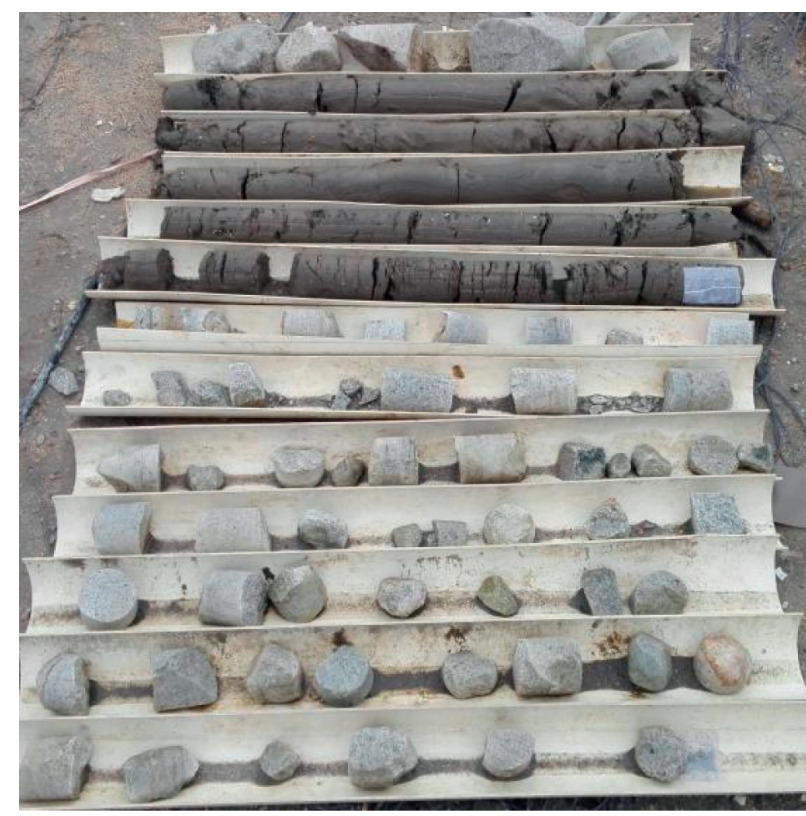

(b)

Figure 3: Rock cores (a) before blasting and (b) after blasting.

Table 1: Physical and mechanical parameters of artificial fill.

\begin{tabular}{lcccc}
\hline Density $\rho\left(\mathrm{g} / \mathrm{cm}^{3}\right)$ & Poisson's ratio $u$ & Cohesion $(\mathrm{KPa})$ & Shear modulus $(\mathrm{MPa})$ & Angle of internal friction $(\mathrm{rad})$ \\
\hline 1.98 & 0.35 & 100 & 150 & 0.31 \\
\hline
\end{tabular}

TABle 2: Physical and mechanical parameters of rock and silt.

\begin{tabular}{|c|c|c|c|c|c|c|c|c|}
\hline & $\begin{array}{l}\text { Density } \rho \\
\left(\mathrm{g} \cdot \mathrm{cm}^{-3}\right)\end{array}$ & $\begin{array}{c}\text { Elastic modulus } \\
E(\mathrm{GPa})\end{array}$ & $\begin{array}{l}\text { Poisson's } \\
\text { ratio } u\end{array}$ & $\begin{array}{c}\text { P wave } \\
\text { velocity }(\mathrm{m} / \mathrm{s})\end{array}$ & $\begin{array}{l}\text { Yield strength } \\
\qquad(\mathrm{MPa})\end{array}$ & $\begin{array}{c}\text { Tangent } \\
\text { modulus }(\mathrm{GPa})\end{array}$ & $\begin{array}{l}\text { Hardening } \\
\text { parameter }\end{array}$ & $\begin{array}{c}\text { Strain rate } \\
\text { parameter } \\
C\end{array}$ \\
\hline Rock & 2.5 & 0.74 & 0.25 & 5357 & $3.0 \mathrm{e}-5$ & 0.042 & 1.0 & 0.06 \\
\hline Silt & 1.63 & $3.3 e-5$ & 0.45 & 1250 & $4.0 \mathrm{e}-9$ & 0.0 & - & - \\
\hline
\end{tabular}

as the center. The schematic diagram of explosion source and measuring points is shown in Figure 6.

\section{Analysis of the Characteristics of Blasting Vibrations of Ground}

4.1. Analysis of the Characteristics of Vibration Acceleration. The first blasting was carried out at 10:00 a.m. on March 31, 2016, and the second blasting was carried out at 3:00 p.m. on March 31, 2016, with an interval of 10 days, and the third blasting was carried out at 10:00 a.m. on April 10, 2016. The vibration acceleration test points were all 10 meters away from the explosion source, and the results of three tests of blasting are shown in Table 3.

The waveform duration of vibration accelerations of three blasting is shown in Figure 7.
As shown in the acceleration waveform of blasting vibrations from Figure 7, the peak particle acceleration of the three blasting vibrations has little difference to each other; the duration of acceleration waveform is about $0.4 \mathrm{~s}$ at $10: 00$ a.m. on March 31, 2016, in the first blasting, and about $0.8 \mathrm{~s}$ at 3:00 p.m. on March 31, 2016, in the second blasting, which is $0.4 \mathrm{~s}$ longer than the duration of the first blasting, with an interval of 10 days, and in the third blasting at 10:00 a.m. on April 10, 2016, the duration of acceleration waveform is about $0.5 \mathrm{~s}$, which is close to the duration of the first blasting.

The above data show that the silt has a good structural strength during the first blasting, but after the disturbance of the blasting load, the silt has been thixotropic liquefied [18]. During the second blasting with a short time interval, the explosive gas generates a cavity in the silt after the explosion. When the pressure of the explosive gas is less than the 

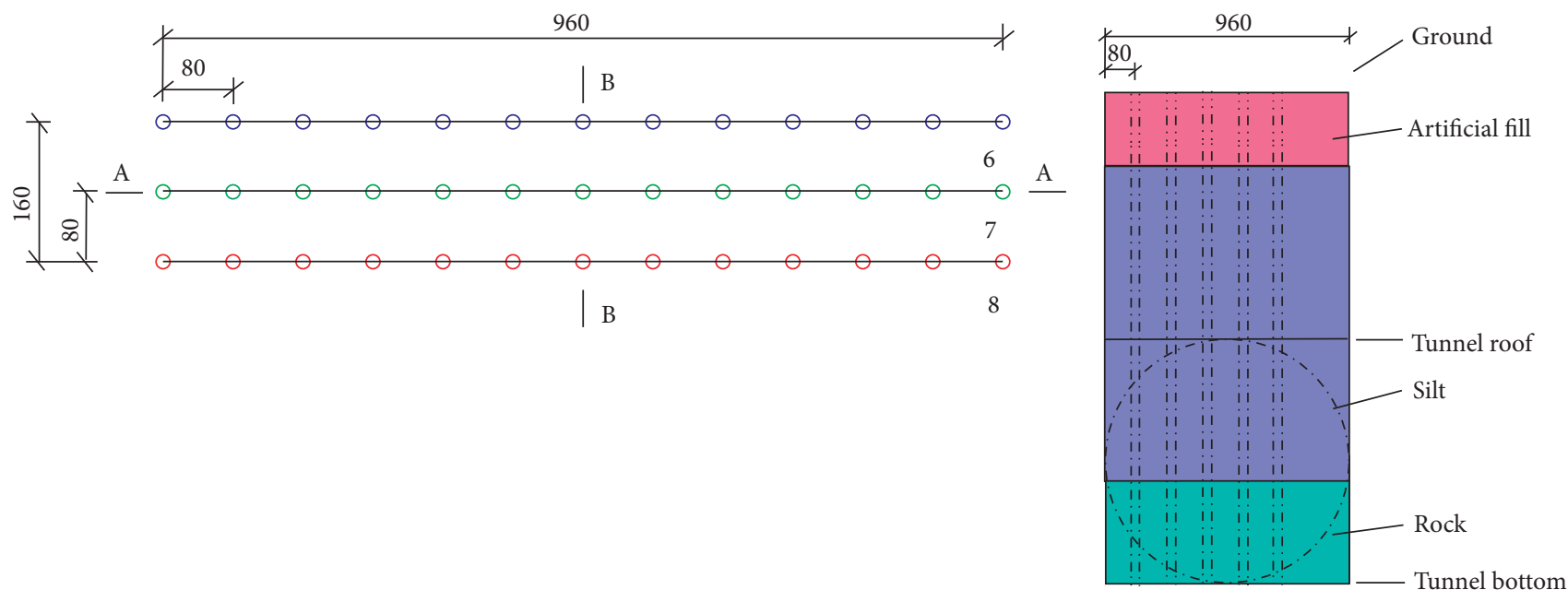

(a)

(b)

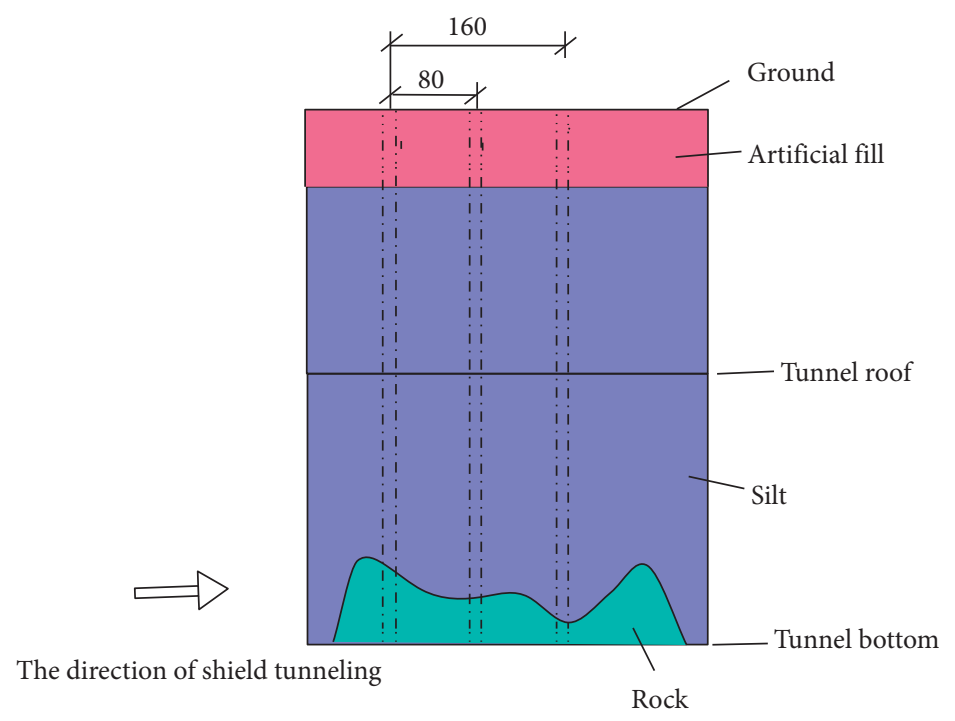

(c)

Figure 4: Sketch map of blastholes (cm). (a) Planar graph, (b) cross section of A-A, and (c) cross section of B-B.

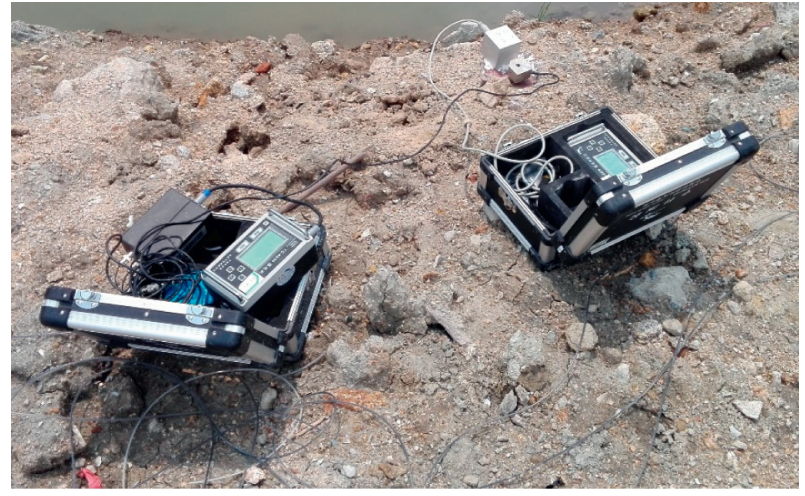

FIGURE 5: Arrangement of blasting vibration meters.

pressure of the silt outside the cavity, the silt around the cavity begins to compress into the cavity, and then, the cavity comes into being. The cavity is overcompressed, and then, the cavity expands again to work on the silt. In the process of pulsation, the water and stemming materials in the blast hole are continuously pushed out of the blast hole until they reach the orifice and escape when they come into contact with the atmosphere, which results in the extension of the waveform duration of acceleration in the second blasting. During the third blasting, the duration of acceleration waveform is close to that of the first blasting, which indicates that after a period of sedimentation, the silt has recovered a certain structural strength.

4.2. Analysis of the Distribution Characteristics of the Dominant Frequency of Blasting Vibration Velocity. Based on the analysis of the dominant frequency of vibration velocity of the three blasting tests in Table 3, it is concluded that the dominant frequency of vibration velocity of the first blasting is between 30 and $60 \mathrm{~Hz}$, which indicates that the silt has good structural strength; during the second blasting, the silt undergoes thixotropic liquefaction after the disturbance 


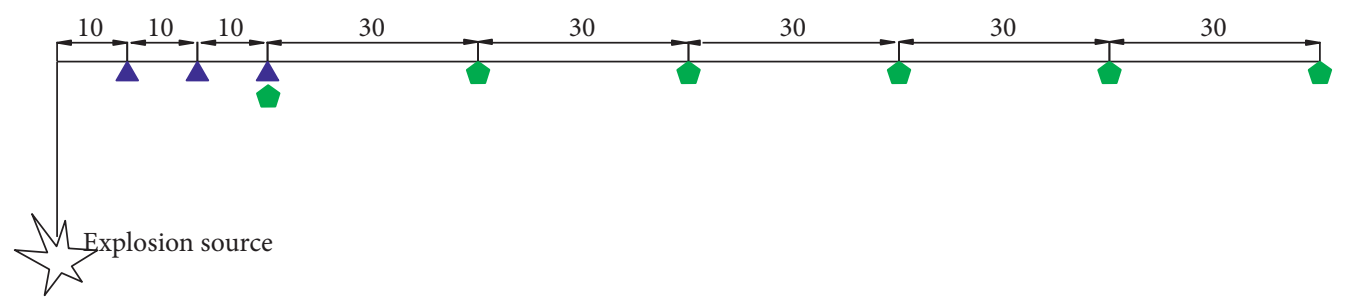

- Measurement point of acceleration

Measurement point of velocity

FIGURE 6: Schematic diagram of explosion source and measuring points $m$.

TABLE 3: Results of three tests of blasting.

\begin{tabular}{|c|c|c|c|c|c|}
\hline & \multirow[t]{2}{*}{ The total explosives $(\mathrm{kg})$} & \multirow[t]{2}{*}{ The maximum charge of one section $(\mathrm{kg})$} & \multirow[t]{2}{*}{ Sections } & \multicolumn{2}{|c|}{$\begin{array}{c}\text { The } \\
\text { dominant } \\
\text { frequency } \\
(\mathrm{Hz})\end{array}$} \\
\hline & & & & $X$ & 47.06 \\
\hline \multirow[t]{3}{*}{ The first blasting } & 43.2 & 34.8 & $5,6,7$ & $Y$ & 55.56 \\
\hline & & & & $Z$ & 36.04 \\
\hline & & & & $X$ & 10.34 \\
\hline \multirow[t]{3}{*}{ The second blasting } & 432.0 & 150.0 & $5,6,7$ & $Y$ & 8.32 \\
\hline & & & & $Z$ & 14.60 \\
\hline & & & & $X$ & 36.70 \\
\hline \multirow[t]{2}{*}{ The third blasting } & 331.2 & 115.2 & $5,7,8$ & $Y$ & 37.38 \\
\hline & & & & $Z$ & 66.67 \\
\hline
\end{tabular}

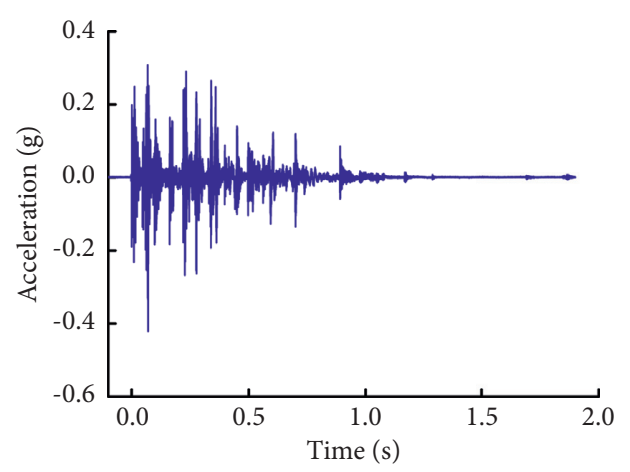

(a)

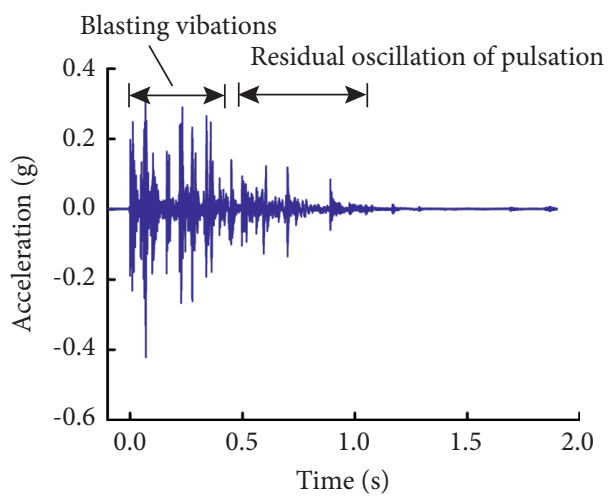

(b)

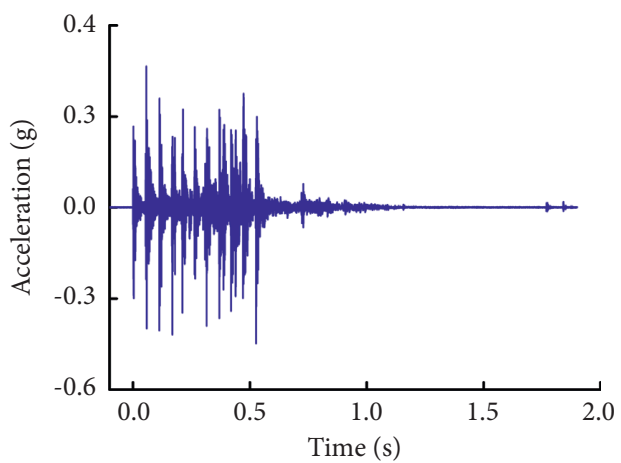

(c)

Figure 7: Acceleration waveform of blasting vibrations, (a) acceleration waveform of the first blasting, (b) acceleration waveform of the second blasting, and (c) acceleration waveform of the third blasting. 
of the first blasting load. The dominant vibration frequency of dynamic velocity is reduced to $5-15 \mathrm{~Hz}$, which is close to the natural vibration frequency of the building, and it is easy to cause the building resonance. At 10:00 am on April 10, 2016, the dominant frequency of the blasting vibration velocity is between 30 and $70 \mathrm{~Hz}$ during the third blasting, and the analysis shows that the structural strength of the silt has been restored due to 10 days from the last blasting. Therefore, the continuous blasting operation should be avoided in the field blasting. Each blasting operation should be separated for a period of time, and the next blasting will be beneficial to reduce the vibration damage until the silt recovers structural strength.

\subsection{Energy Percentage of Each Frequency Bands of Blasting} Vibrations. Taking a typical test data of blasting vibrations as an example, the field monitoring data of blasting vibrations are shown in Table 4, and the time history curves of velocity of measured blasting vibration signals are shown in Figure 8.

4.3.1. Reconstruction Error. The signals of blasting vibrations belonged to random signals. At present, the $\mathrm{db} 8$ wavelet basis function was widely used to analyze the nonstationary vibration signal [19-21]. The error of wavelet reconstruction signal based on db8 is shown in Figure 9.

It could be seen from Figure 9 that using db8 wavelet basis function to decompose the vibration signals in 8 layers, the relative error magnitude between the reconstructed signal and the original signal was $10^{-11}$, which met the analysis requirements.

4.3.2. Decomposition and Reconstruction. Using $\mathrm{db} 8$ wavelet basis function to decompose the signal of blasting vibrations with the scale of 8 , the wavelet coefficients of 9 frequency bands were obtained [22]. During blasting vibration monitoring, the sampling frequency of the signal was set to $8000 \mathrm{~Hz}$ ( $2 \mathrm{~s}$ sampling 16000 points). According to the Shannon sampling theorem [21], the Nyquist frequency of sampling was $4000 \mathrm{~Hz}$. According to the principle of wavelet decomposition [23], the bandwidth of nine wavelets was a8: $0-15.625 \mathrm{~Hz}, \mathrm{~d} 8: 15.625-31.25 \mathrm{~Hz}, \mathrm{~d} 7: 31.25-62.5 \mathrm{~Hz}, \mathrm{~d} 6$ : $62.5-125 \mathrm{~Hz}, \quad \mathrm{~d} 5: \quad 125-250 \mathrm{~Hz}, \quad \mathrm{~d} 4: \quad 250-500 \mathrm{~Hz}, \quad \mathrm{~d} 3$ : $500-1000 \mathrm{~Hz}, \mathrm{~d} 2: 1000-2000 \mathrm{~Hz}$, and d1: $2000-4000 \mathrm{~Hz}$. The blasting vibration components of different wavelet frequency bands are shown in Figure 10.

4.3.3. Percentage of Energy per Frequency Band. The statistics of energy percentage of each wavelet band of blasting vibration signals in different directions are shown in Table 5.

During blasting rock in silt-rock strata, the frequency bands of ground vibration energy are wide, but the frequency bands are mainly concentrated in $0-15.625 \mathrm{~Hz}$, $31.25-62.5 \mathrm{~Hz}$, and $62.5-125 \mathrm{~Hz}$, which are accounting for more than $90 \%$ of the total signal energy. The dominant frequency bands of blasting vibration energy are in $0-15.625 \mathrm{~Hz}$, which are close to the natural frequency of buildings and have a great impact on the vibration damage of surface buildings.

The high-frequency signals above $125 \mathrm{~Hz}$ continue the whole monitoring period, which are represented by noise signal, with relatively small energy, and limited impact on surface buildings.

\subsection{The Energy of Each Frequency Bands of Blasting} Vibrations. Taking the test data of the first blasting vibrations on the morning of March 31, 2016, as an example, the distance between the test point and the explosion source was $60 \mathrm{~m}$, and the energy distributions of each wavelet band in different directions are shown in Figure 11.

It can be seen from Figure 11 that the distribution characteristics of the frequency bands of blasting vibration energy in different directions of the ground are similar to each other, but the energy magnitudes are different from each other.

The wavelet energy analysis was carried out on the six test data of blasting vibrations of rock blasting in silt-rock strata, and the directions of the maximum energy are shown in Table 6.

According to Table 6, when the distance of the test points from the explosion source is in the range of $30-60 \mathrm{~m}$, the number of times of maximum energy in $Z$ direction is 8 , and the number of times of maximum energy in $X$ direction is 4 .

According to the analysis, because of the end effect of the cylindrical charge, there is air above the ground, without clamping effect, and there are more times of maximum energy in the $Z$ direction; when the amount of cylindrical charge is less, the end effect is not obvious, and the explosion stress waves propagate outward in the form of cylinder, 13 blastholes in a row produce a cylinder wave, and the cylinder wave would overlap at the measuring point, so there are 4 times in the $X$ direction.

When the distance of the test point from the explosion source is in the range of $90-180 \mathrm{~m}$, the number of times of maximum energy is 15 in the $Z$ direction, 4 in the $X$ direction, and 3 in the $Y$ direction. It is considered that the maximum number of times of energy in the $X$ direction and $Y$ direction is the most due to the influence of pinch effect on explosion stress wave in the $Z$ direction.

The times of the maximum energy in the $Z$ direction are the most, followed by the $X$ direction when the distance of the test point from the explosion source is in the range of $30-60 \mathrm{~m}$. Because the vibration energy in the $Z$ direction is the largest and easy to cause up and down vibration damage to the building, the blasting vibration energy in the $Z$ direction should be focused on analysis, followed by the $X$ direction.

The vibration energy in the $Z$ direction is mainly analyzed when the distance of the test point from the explosion source is in the range of $90-180 \mathrm{~m}$.

4.5. Attenuation Laws of Vibration Velocity of Rock Blasting in Silt-Rock Strata. To study the attenuation laws of vibration velocity of rock blasting in the silt-rock strata, four vibration velocity tests were carried out in the blasting area. Six 
TABLE 4: Field monitoring data of blasting vibrations.

\begin{tabular}{|c|c|c|c|c|c|c|}
\hline \multirow{2}{*}{ The total explosives $(\mathrm{kg})$} & \multirow{2}{*}{ The maximum charge of one section $(\mathrm{kg})$} & \multirow{2}{*}{ Sections } & \multirow{2}{*}{ The distance from explosion source $(\mathrm{m})$} & \multicolumn{3}{|c|}{$\mathrm{PPV}(\mathrm{cm} / \mathrm{s})$} \\
\hline & & & & $\mathrm{X}$ & $\mathrm{Y}$ & $\mathrm{Z}$ \\
\hline 432 & 150 & $5,6,7$ & 130 & 0.15 & 0.13 & 0.10 \\
\hline
\end{tabular}

Note. $X$ was the horizontal direction pointing to the explosion source, $Y$ was the horizontal direction perpendicular to $X$, and $Z$ was the vertical direction.

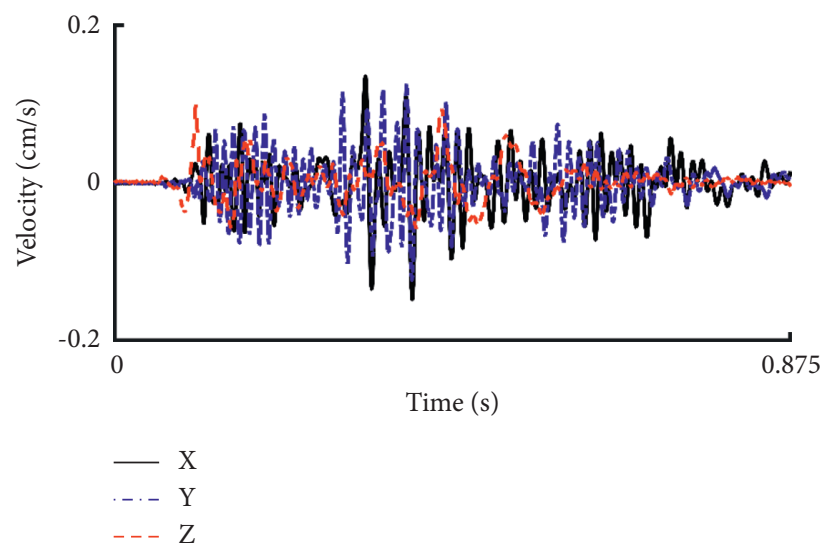

FIGURE 8: Time history curves of velocity of measured blasting vibrations.

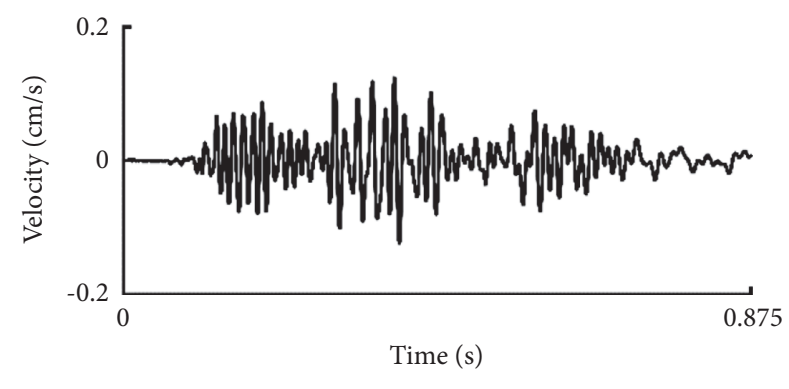

(a)

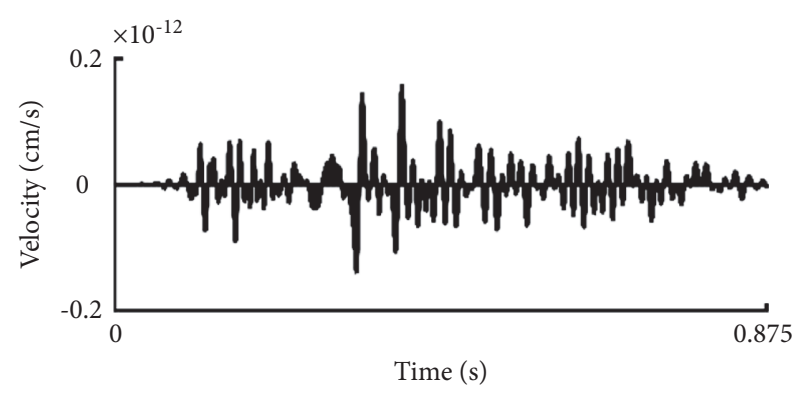

(b)

FiguRE 9: Wavelet reconstruction and error based on db8. (a) Original blasting vibration signals and (b) error of reconstructed signals.

measuring points of vibration velocity were arranged for each test. The test results of blasting vibration velocity are shown in Table 7.

\subsubsection{Prediction Model of Blasting Vibration Velocity Based} on $D A$. Natural phenomena and engineering problems could be described by a series of physical quantities. To find the laws between these physical quantities, firstly, we could list the physical quantities that involved in these problems, ignore some physical quantities with less influence, and then classify the physical quantities involved according to their attributes; secondly, we could find out the interrelations between different physical quantities; and finally, we could find out the causal relationship between some physical quantities and the other physical quantities.

There were relations among all kinds of physical quantities, which showed that their structure must be composed of several unified basic components. This basic component of physical quantity was called dimension. Because physics studied the evolution and movement of matter in space and time, all quantitative problems could not be separated from the three basic quantities of mass $(M)$, time $(T)$, and length $(L)$. Therefore, $M, T$, and $L$ were the most suitable dimensions for these three basic quantities. The dimensions of all other derived quantities could be expressed as the combination of these three basic quantities according to the definition or objective laws.

The attenuation of seismic wave was affected by the factors of explosion source, geological conditions, distance of explosion source, and depth of explosion source when the blasting seismic wave propagated in silt-rock strata [24, 25]. There were 9 physical quantities involved in propagation velocity in silt-rock strata $[26,27]$, as shown in Table 8.

Based on the DA of Buckingham's theorem ( $\pi$ theorem), the PPV $v$ of the ground during the rock blasting in the siltrock strata could be expressed as follows:

$$
v=\Phi(S, \rho, H, a, f, t, Q, r, c) .
$$


Shock and Vibration

9

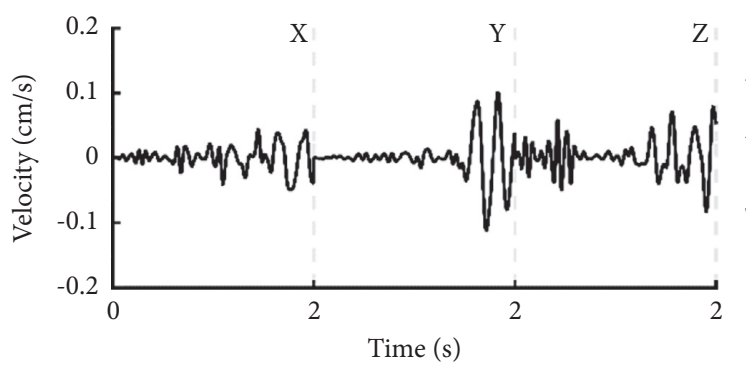

as

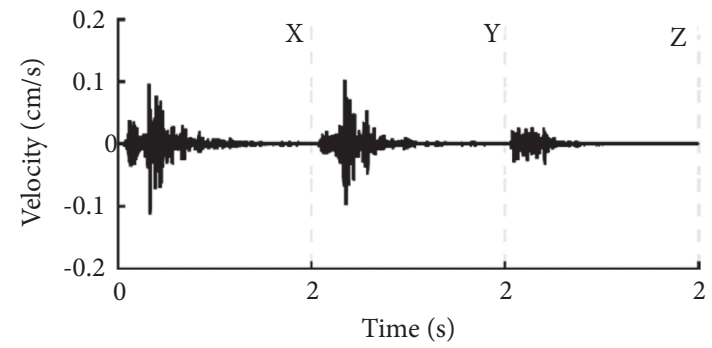

d7

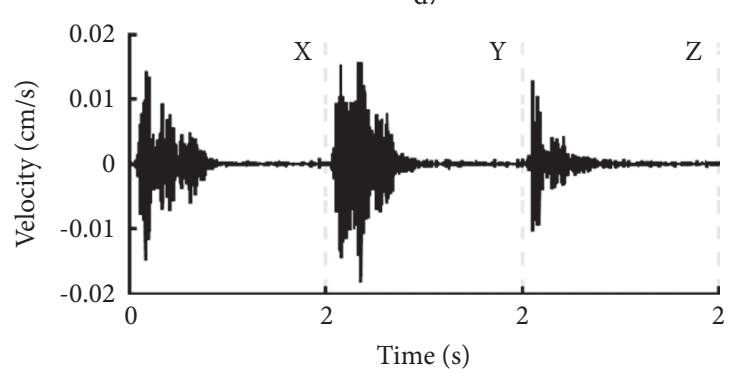

di

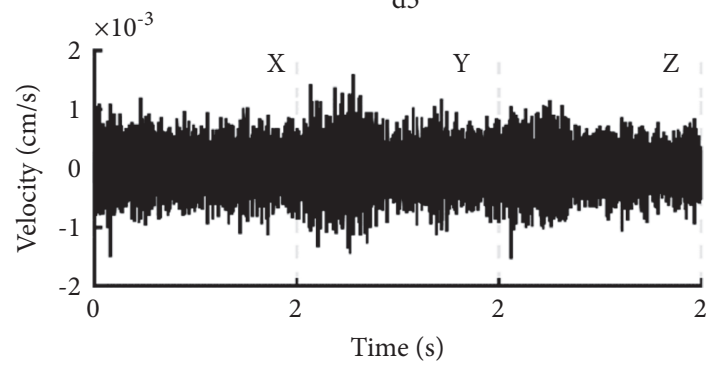

d3

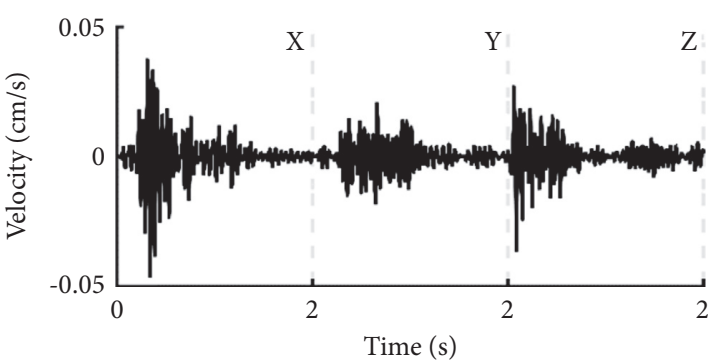

do

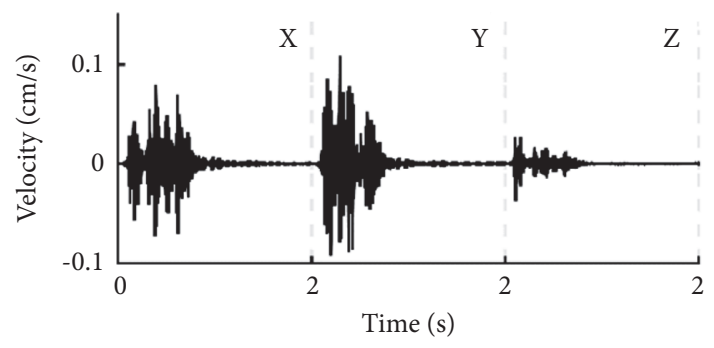

do

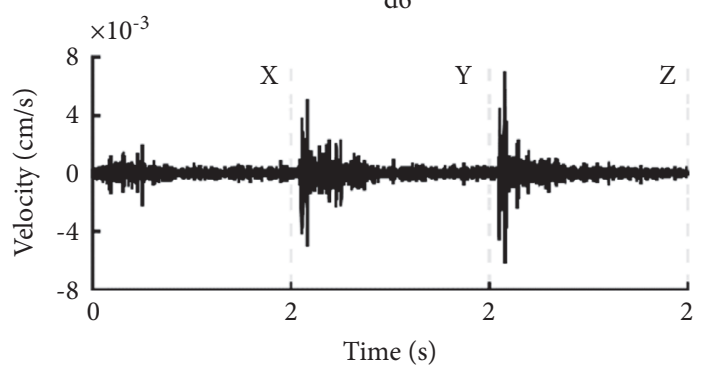

dy

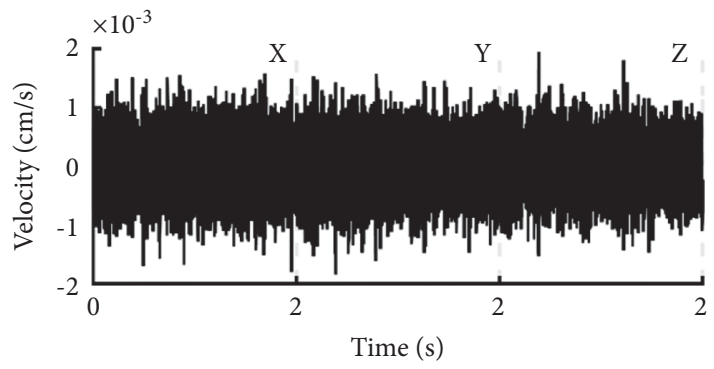

de

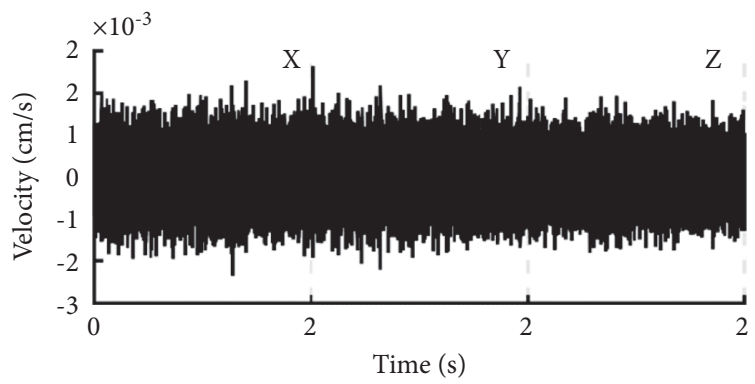

di

Figure 10: Stratified reconstruction of signals by wavelet decomposition. 
TABLE 5: Energy percentage of each frequency band in different directions (\%).

\begin{tabular}{lccccccccc}
\hline Frequency bands & $\mathrm{a} 8$ & $\mathrm{~d} 8$ & $\mathrm{~d} 7$ & $\mathrm{~d} 6$ & $\mathrm{~d} 5$ & $\mathrm{~d} 4$ & $\mathrm{~d} 3$ & $\mathrm{~d} 2$ & $\mathrm{~d} 1$ \\
\hline$X$ & 43.80 & 9.69 & 24.94 & 21.12 & 0.38 & 0.01 & 0.01 & 0.02 & 0.04 \\
$Y$ & 67.02 & 1.81 & 11.25 & 19.41 & 0.46 & 0.01 & 0.01 & 0.01 & 0.02 \\
$Z$ & 88.91 & 4.93 & 4.13 & 1.80 & 0.15 & 0.03 & 0.01 & 0.02 & 0.03 \\
\hline
\end{tabular}

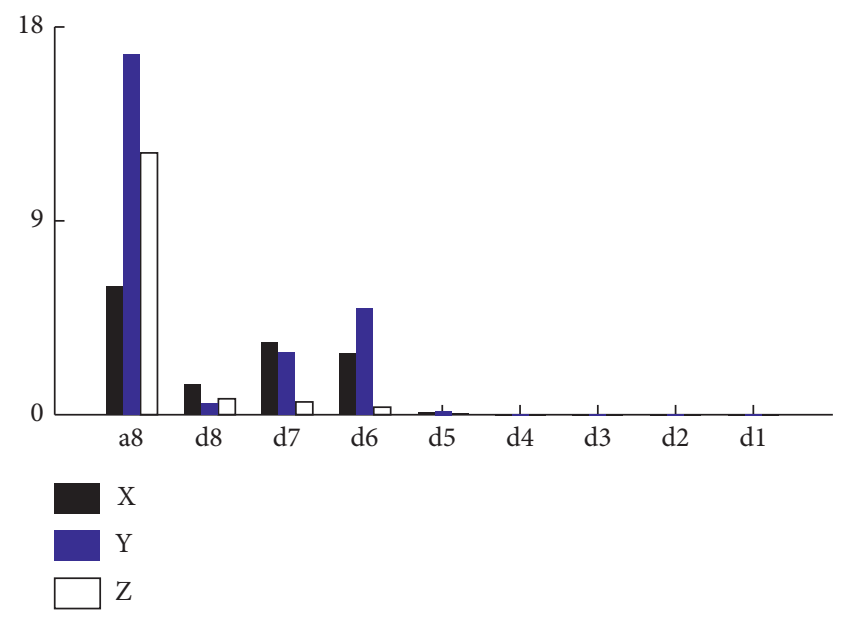

Figure 11: Energy of each frequency bands in different directions $(\mathrm{cm} / \mathrm{s})^{2}$.

TABle 6: Directions of the maximum energy.

\begin{tabular}{|c|c|c|c|c|c|c|}
\hline $\begin{array}{l}\text { The distance from explosion } \\
\text { source }(\mathrm{m})\end{array}$ & The first blasting & $\begin{array}{c}\text { The second } \\
\text { blasting }\end{array}$ & $\begin{array}{l}\text { The third } \\
\text { blasting }\end{array}$ & $\begin{array}{l}\text { The forth } \\
\text { blasting }\end{array}$ & $\begin{array}{l}\text { The fifth } \\
\text { blasting }\end{array}$ & $\begin{array}{l}\text { The sixth } \\
\text { blasting }\end{array}$ \\
\hline 30 & $X$ & $Z$ & $Z$ & $Z$ & $X$ & $Z$ \\
\hline 60 & $Z$ & $X$ & $Z$ & $Z$ & $X$ & $Z$ \\
\hline 90 & $Z$ & $Z$ & $Z$ & $Z$ & $X$ & $Z$ \\
\hline 120 & $Y$ & $Y$ & $X$ & $X$ & $Z$ & $Z$ \\
\hline 150 & $\begin{array}{c}\text { The instrument was not } \\
\text { triggered }\end{array}$ & $Z$ & $Z$ & $Z$ & $Y$ & $Z$ \\
\hline 180 & $Z$ & $Z$ & $X$ & $\begin{array}{c}\text { The instrument was not } \\
\text { triggered }\end{array}$ & $Z$ & $Z$ \\
\hline
\end{tabular}

Note. $X$ was the horizontal direction pointing to the explosion source, $Y$ was the horizontal direction perpendicular to $X$, and $Z$ was the vertical direction.

According to the $\pi$ theorem, where independent dimensions were $Q, r$, and $c$, and $\pi$ represents dimensionless quantities, then,

$$
\left\{\begin{array}{l}
\pi=\frac{v}{Q^{\alpha} r^{\beta} c^{\gamma}}, \pi_{1}=\frac{S}{Q^{\alpha_{1}} r^{\beta_{1}} c^{\gamma_{1}}}, \pi_{2}=\frac{\rho}{Q^{\alpha_{2}} r^{\beta_{2}} c^{\gamma_{2}}}, \\
\pi_{3}=\frac{H}{Q^{\alpha_{3}} r^{\beta_{3}} c^{\gamma_{3}}}, \pi_{4}=\frac{a}{Q^{\alpha_{4}} r^{\beta_{4}} c^{\gamma_{4}}}, \\
\pi_{5}=\frac{f}{Q^{\alpha_{5}} r^{\beta_{5}} c^{\gamma_{5}}}, \pi_{6}=\frac{t}{Q^{\alpha_{6}} r^{\beta_{6}} c^{\gamma_{6}}} .
\end{array}\right.
$$

where $\alpha, \beta$, and $\gamma$ were undetermined coefficients. According to the dimensional homogeneous theorem, there were as follows:

$$
\left\{\begin{array}{l}
\pi=\frac{v}{c}, \pi_{1}=\frac{S}{r}, \pi_{2}=\frac{\rho}{Q r^{-3}}, \\
\pi_{3}=\frac{H}{r}, \pi_{4}=\frac{a}{r^{-1} c^{2}}, \\
\pi_{5}=\frac{f}{r^{-1} c_{c}}, \pi_{6}=\frac{t}{r c^{-1}} .
\end{array}\right.
$$

Substituting (3) into (1) could obtain the following:

$$
\frac{v}{c}=\Phi\left(\frac{S}{r}, \frac{\rho}{Q r^{-3}}, \frac{H}{r}, \frac{a}{r^{-1} c^{2}}, \frac{f}{r^{-1} c}, \frac{t}{r c^{-1}}\right) .
$$

Since the product and power of different dimensionless numbers $\pi$ were still dimensionless, $\pi_{2}$ and $\pi_{3}$ are combined as follows to get a new dimensionless number $\pi_{7}$ : 
TABLE 7: Testing results of blasting vibration velocity.

\begin{tabular}{|c|c|c|c|c|c|c|c|}
\hline \multirow{3}{*}{$\begin{array}{l}\text { Test } \\
\text { times }\end{array}$} & \multirow{3}{*}{$\begin{array}{l}\text { The maximum charge of } \\
\text { one section } Q(\mathrm{~kg})\end{array}$} & \multicolumn{6}{|c|}{ Vibration velocity } \\
\hline & & \multirow{2}{*}{$\begin{array}{c}\text { No. of measuring } \\
\text { point }\end{array}$} & \multirow{2}{*}{$\begin{array}{l}\text { The distance from } \\
\text { explosion source }(\mathrm{m})\end{array}$} & \multicolumn{4}{|c|}{$\mathrm{PPV} v(\mathrm{~cm} / \mathrm{s})$} \\
\hline & & & & $\begin{array}{c}\text { The } X \\
\text { direction }\end{array}$ & $\begin{array}{l}\text { The } Y \\
\text { direction }\end{array}$ & $\begin{array}{c}\text { The } Z \\
\text { direction }\end{array}$ & Resultant \\
\hline \multirow{5}{*}{ No. 1} & \multirow{5}{*}{34.8} & $\mathrm{ZC1}$ & 30 & 1.67 & 1.32 & 1.93 & 1.94 \\
\hline & & $\mathrm{ZC} 2$ & 60 & 0.37 & 0.39 & 0.49 & 0.54 \\
\hline & & ZC3 & 90 & 0.18 & 0.17 & 0.33 & 0.34 \\
\hline & & $\mathrm{ZC} 4$ & 130 & 0.15 & 0.13 & 0.1 & 0.2 \\
\hline & & ZC5 & 170 & 0.04 & 0.06 & 0.09 & 0.1 \\
\hline \multirow{6}{*}{ No. 2} & \multirow{6}{*}{150} & $\mathrm{ZC1}$ & 30 & 4.68 & 3.2 & 8.1 & 8.58 \\
\hline & & $\mathrm{ZC} 2$ & 60 & 6.97 & 3.87 & 4.22 & 7.6 \\
\hline & & $\mathrm{ZC} 3$ & 90 & 0.46 & 0.47 & 0.97 & 1.01 \\
\hline & & $\mathrm{ZC4}$ & 120 & 1.11 & 1.14 & 0.81 & 1.36 \\
\hline & & ZC5 & 150 & 0.34 & 0.39 & 0.62 & 0.63 \\
\hline & & ZC6 & 180 & 0.34 & 0.14 & 0.48 & 0.49 \\
\hline \multirow{5}{*}{ No. 3} & \multirow{5}{*}{165.6} & $\mathrm{ZC1}$ & 30 & 4.95 & 3.1 & 15.3 & 15.36 \\
\hline & & $\mathrm{ZC} 2$ & 60 & 2.37 & 1.75 & 8.05 & 8.25 \\
\hline & & ZC3 & 90 & 1.22 & 0.84 & 2.09 & 2.09 \\
\hline & & $\mathrm{ZC4}$ & 120 & 0.73 & 0.36 & 0.83 & 0.87 \\
\hline & & ZC5 & 150 & 0.01 & 0.017 & 0.0057 & 0.017 \\
\hline \multirow{6}{*}{ No. 4} & \multirow{6}{*}{54} & $\mathrm{ZC1}$ & 30 & 2.13 & 0.68 & 0.63 & 0.63 \\
\hline & & $\mathrm{ZC2}$ & 60 & 0.57 & 0.68 & 0.38 & 1.41 \\
\hline & & ZC3 & 90 & 1.6 & 0.82 & 0.5 & 1.61 \\
\hline & & $\mathrm{ZC4}$ & 120 & 0.37 & 0.26 & 2.1 & 2.12 \\
\hline & & ZC5 & 150 & 0.22 & 0.18 & 1.02 & 1.03 \\
\hline & & ZC6 & 180 & 0.18 & 0.12 & 0.63 & 0.63 \\
\hline
\end{tabular}

TABLE 8: Physical quantities involved in blasting vibration velocity in silt-rock strata.

\begin{tabular}{lcc}
\hline & Variables & Dimensions \\
\hline The dependent variables & Particle vibration displacement $S$ & $\mathrm{~L}$ \\
$\mathrm{LT}^{-1}$ & $\mathrm{PPV} v$ & $\mathrm{LT}^{-2}$ \\
$\mathrm{~T}^{-1}$ & Peak particle acceleration $\alpha$ & $\mathrm{M}$ \\
The independent variables & Frequency of particle vibration $f$ & $\mathrm{~L}$ \\
& Quality of explosives $Q$ & $\mathrm{~L}$ \\
& Horizontal distance between the test point and the explosion source $r$ & $\mathrm{ML}^{-3}$ \\
$\mathrm{LT}^{-1}$ & Depth of explosion source $H$ & $\mathrm{~T}$ \\
\hline
\end{tabular}

Note. $L, T$, and $M$ were dimensions of length, time, and mass, respectively.

$$
\pi_{7}=\left(\pi_{2}^{1 / 3}\right)^{\beta_{1}} \pi_{3}^{\beta_{2}}=\left(\frac{\sqrt[3]{\rho} r}{\sqrt[3]{Q}}\right)^{\beta_{1}}\left(\frac{H}{r}\right)^{\beta_{2}}
$$

where $\beta_{1}$ and $\beta_{2}$ were the indexes of $\pi_{2}$ and $\pi_{3}$, respectively.

At the same site, $\rho$ and $c$ could be approximately constant. Therefore, from (5), it could be considered that $v$ and $(\sqrt[3]{\mathrm{Q}} / r)^{\beta_{1}}(H / r)^{\beta_{2}}$ had a functional relationship.

To sum up, this functional relationship could be expressed as follows:

$$
\ln v=\left[\alpha_{1}+\beta_{1} \ln \left(\frac{\sqrt[3]{Q}}{r}\right)\right]+\left[\alpha_{2}+\beta_{2} \ln \left(\frac{H}{r}\right)\right] .
$$

If $\ln v_{0}=\alpha_{1}+\beta_{1} \ln (\sqrt[3]{Q} / R)$., there were as follows:

$$
\ln v_{0}=\alpha_{1}+\frac{\left(\beta_{1} \ln Q\right)}{3}-\beta_{1} \ln r \text {. }
$$

In equation (6), $\alpha_{1}$ and $\alpha_{2}$ were the coefficients given in the process of function transformation; $-\beta_{1} \ln r$ was the attenuation of blasting vibration velocity with distance $r ; \beta_{1}$ was the attenuation index, which mainly reflected the effect of site medium conditions; and $\alpha_{1}+\left(\beta_{1} \ln Q\right) / 3$ comprehensively reflected the contribution of site medium conditions and explosive quantity to the PPV of ground.

If $\ln k_{1}=\ln \alpha_{1}$, there were as follows:

$$
v_{0}=k_{1}\left(\frac{\sqrt[3]{Q}}{r}\right)^{\beta_{1}} .
$$

Equation (8) was Sadovski's equation. without the effect of the depth of explosion source. Substituting (8) into (6), we could get the following: 
TABLe 9: Prediction model of attenuation laws of blasting vibration velocity.

\begin{tabular}{lcccc}
\hline Direction & Equation $(8)$ & Correlation coefficient & Equation $(11)$ & Correlation coefficient \\
\hline$X$ & $v=152.93(\sqrt[3]{\mathrm{Q}} / r)^{1.89}$ & 0.60 & $v=237.46(\sqrt[3]{\mathrm{Q}} / r)^{2.13}(H / r)^{-0.28}$ & 0.62 \\
$Y$ & $v=63.43(\sqrt[3]{\mathrm{Q}} / r)^{1.67}$ & 0.63 & $v=92.76(\sqrt[3]{\mathrm{Q}} / r)^{1.88}(H / r)^{-0.24}$ & 0.65 \\
$Z$ & $v=107.77(\sqrt[3]{\mathrm{Q}} / r)^{1.66}$ & 0.38 & $v=340.36(\sqrt[3]{\mathrm{Q}} / r)^{2.30}(H / r)^{-0.73}$ & 0.42 \\
Resultant & $v=114.43(\sqrt[3]{\mathrm{Q}} / r)^{1.59}$ & 0.43 & $v=333.62(\sqrt[3]{\mathrm{Q} / r})^{2.19}(H / r)^{-0.68}$ & 0.47 \\
\hline
\end{tabular}

$$
\ln v=\ln v_{0}+\left[\alpha_{2}+\beta_{2} \ln \left(\frac{H}{r}\right)\right] .
$$

If $\ln k_{1}=\ln \alpha_{1}$, then (9) could be changed into the following:

$$
v=k_{1} k_{2}\left(\frac{\sqrt[3]{Q}}{r}\right)^{\beta_{1}}\left(\frac{H}{r}\right)^{\beta_{2}} .
$$

If $k=k_{1} k_{2}$, the mathematical model of the attenuation laws of blasting vibration velocity in silt-rock strata considering the effect of burial depth was established as follows:

$$
v=k\left(\frac{\sqrt[3]{Q}}{r}\right)^{\beta_{1}}\left(\frac{H}{r}\right)^{\beta_{2}}
$$

where $k$ was the site effect coefficient, $\beta_{1}$ was the attenuation coefficient of blasting vibrations, and $\beta_{2}$ was the effect coefficient of explosion source depth.

\subsubsection{Comparative Analysis of Prediction Results of Blasting} Vibration Velocity. The explosion source was below the ground surface during blasting rock in silt-rock strata, while measuring points of blasting vibration velocity were often located on the ground surface, which was also the key content of the analysis of attenuation laws of blasting vibrations. Therefore, this study selected the ground data for analysis and established the prediction model of vibration velocity of rock blasting in silt-rock strata. According to Z. C. Zhang's research [28], the attenuation laws of vibration velocity near blasting zone were different from the attenuation laws of vibration velocity far blasting zone. $\bar{R}=r / Q^{1 / 3}$ was the scaled distance, $r$ was the horizontal distance between the test point and the explosion source, and $Q$ was the quality of explosives. The $\bar{R}<5.0$ was in the near blasting zone. The $\bar{R}$ of monitoring data in this paper is greater than 5.0 , and the monitoring data were not within the range of near blast area. The monitoring data could be used to analyze the attenuation law. Equation (11) in Section 4.5.1 is used for regression fitting analysis of the blasting vibration data listed in Table 7 to obtain the prediction model of vibration velocity of rock blasting in the silt-rock strata.

In regression analysis, the correlation coefficient was an indicator to measure the linear correlation between variables. The larger the correlation coefficient was, the smaller the error was, the higher the linear correlation between variables was, the higher the reliability of the prediction model was, and vice versa. To determine the accuracy of the established mathematical model, the established mathematical model (11) was compared with the traditional Sadovski's formula (8) and the prediction accuracy of the two eqns. for blasting vibration velocity was evaluated according to the correlation coefficient of the fitting curve. The analysis results are shown in Table 9.

It can be concluded from Table 9:

(1) According to the obtained prediction model of vibration velocity considering the explosion depth, using the control variable method, it can be found that with the increase in horizontal distance, the PPV decreases; with the increase in explosive quantity, the PPV increases; and with the increase in explosion depth, the PPV decreases; this is consistent with the results of the paper analysis and common sense. It is shown that the prediction model of vibration velocity of rock blasting in siltrock strata established is effective in predicting PPV of ground.

(2) The correlation coefficient obtained by fitting 4.5 section blasting vibration velocity data by using the vibration velocity prediction model (equation (11)) considering explosion depth is greater than that of traditional Sadovski's formula (equation (8)), which indicates that the attenuation laws of ground blasting vibrations in silt-rock strata are more complex, and the mathematical prediction model established in this study can better reflect the effect of rock blasting vibrations on the ground in silt-rock strata.

\section{Conclusions}

Based on the analysis of vibration characteristics of rock blasting in silt-rock strata, the following conclusions are drawn:

(1) In the first blasting, the silt has good structural strength, and in the second blasting with an interval of 5 hours, the silt is subject to thixotropic liquefaction after the disturbance of blasting load. When the third blasting is carried out with an interval of 10 days, the waveform duration of acceleration is close to that of the first blasting waveform, and the dominant frequency of blasting vibration velocity is close to that of the first blasting too. It is considered that after a period of sedimentation, the silt recovered to a certain structural strength, and the residual oscillation of pulsation is weakened.

(2) The distribution of frequency bands of vibration energy is wide, but they are mainly concentrated in the range of $0-15.625 \mathrm{~Hz}, 31.25-62.5 \mathrm{~Hz}$, and $62.5-125 \mathrm{~Hz}$, and they are accounting for more than $90 \%$ of the total energy of signals during blasting 
rock. The dominant frequency bands of blasting vibration energy are in the range of $0-15.625 \mathrm{~Hz}$.

(3) The distribution characteristics of frequency bands of blasting vibration energy in different directions are similar to each other during blasting rock, but the energy magnitudes are different from each other. The times of maximum energy in $Z$ direction are the most, followed by $X$ direction when the distance from the explosion source is in the range of $30-60 \mathrm{~m}$. The blasting vibration energy in $Z$ direction should be selectively analyzed, followed by $X$ direction. The blasting vibration energy in $Z$ direction should be mainly analyzed when the distance from the explosion source is in the range of $90-180 \mathrm{~m}$.

(4) The correlation coefficients of the prediction model based on the DA are greater than that of the traditional Sadovski's formula through fitting the measured blasting vibration data.

\section{Data Availability}

The processed data required to reproduce these findings cannot be shared at this time as the data also form part of an ongoing study.

\section{Conflicts of Interest}

The authors declare that they have no conflicts of interest.

\section{Acknowledgments}

This study was sponsored by the National Natural Science Foundation of China (Grant no. 41972286), the Fund for Talent Introduction, Anhui University of Science and Technology (no. 13190208), and the Program for Innovation Training (no. S202110361067).

\section{References}

[1] Z.-L. Chen, J.-Y. Chen, H. Liu, and Z.-F. Zhang, "Present status and development trends of underground space in Chinese cities: evaluation and analysis," Tunnelling and Underground Space Technology, vol. 71, pp. 253-270, 2018.

[2] L. Chong, "Study on construction technology of deep hole blasting pretreatment for shield passing through upper soft and lower hard strata," Technology and Market, vol. 8, no. 8, pp. 32-35, 2015.

[3] Z. Q. Wu, "Key construction technology of boulder and bedrock bulge treatment in cross sea shield tunnel," Jiangxi Building Materials, vol. 3, no. 5, pp. 181-183, 2016.

[4] X. L. Pan and Q. H. Ren, "Application of deep hole blasting technology without free face in subway construction," Construction and Architecture, vol. 8, pp. 70-71, 2011.

[5] L. J. Zheng, "Shield tunneling technology in boulder stratum," Railway Construction Technology, vol. 7, pp. 11-13, 2014.

[6] Z. S. Yang, W. F. Xing, and J. S. Ren, "The propagation law of shock wave in silt under explosion," in Proceedings of the 4th National Engineering Blasting Academic Conference, Metallurgical industry press, Beijing, China, 1989.
[7] X. Li, J. Ma, H. Y. Li, L. Fan, and Z. J. Wen, "Analysis of vibration effects to deep and thick silt by blasting compaction," Hydro-Science and Engineering, vol. 2, pp. 71-77, 2016.

[8] X. Y. Xu, R. Wang, Q. S. Meng, and J. Hao, "Monitoring and controlling technology for vibration effect due to deep and thick silt by blasting compaction," Rock and Soil Mechanics, vol. 29, pp. 3256-3259, 2016.

[9] W. Wei, The Transmission Characteristics of Blast Shock Wave in Soft Soil, Ningbo University, Ningbo, China, 2015.

[10] C. Wa and J. Martin, "Blast induced liquefaction potential influence of unsaturated conditions," Blast Induced Liquefaction Potential Influence of Unsaturated Conditions, pp. 1-32, 1979.

[11] S. V. Mikulyak, "Calculation of the formation processes of underground cavities by blasting method," Journal of Mining Science, vol. 36, no. 2, pp. 133-140, 2000.

[12] D. Huang, S. Cui, and X. Li, "Wavelet packet analysis of blasting vibration signal of mountain tunnel," Soil Dynamics and Earthquake Engineering, vol. 117, pp. 72-80, 2019.

[13] Y. Yang, W. Sun, and S. F. Li, "Research to blasting vibration distribution of an open pit mine based on wavelet packet theory," Applied Mechanics and Materials, vol. 130-134, pp. 1547-1555, 2011.

[14] J. Pyra and A. Sołtys, "Method for studying the structure of blast-induced vibrations in open-cast mines," Journal of Vibroengineering, vol. 18, no. 6, pp. 3829-3840, 2016.

[15] M. Khandelwal and M. Saadat, "A dimensional analysis approach to study blast-induced ground vibration," Rock Mechanics and Rock Engineering, vol. 48, no. 2, pp. 727-735, 2014.

[16] H. Dehghani and M. Ataee-Pour, "Development of a model to predict peak particle velocity in a blasting operation," International Journal of Rock Mechanics and Mining Sciences, vol. 48, no. 1, pp. 51-58, 2011.

[17] A. J. Olarewaju, A Study on the Dynamic Dimensionless Behaviors of Underground Pipes Due to Blast Loads Using Finite Element Method, Earthquake engineering, London, United Kingdom, 2015.

[18] N. H. Yang, Blasting Vibration Theory and Control Technology, China Railway Publishing House, China, 2014.

[19] C. Wu, C. B. Zhou, N. Jiang et al., "Wavelet energy analysis of blasting vibration of mining slope in open pit to underground transition," Blasting, vol. 32, pp. 104-108, 2015.

[20] J. W. Yan, Y. Long, X. Fang, and Z. C. Hua, "Analysis on features of energy distribution for blasting seismic wave based on wavelet transform," Explosion and Shock Waves, vol. 27, no. 5, pp. 405-410, 2007.

[21] X. Tian, Z. Song, and J. Wang, "Study on the propagation law of tunnel blasting vibration in stratum and blasting vibration reduction technology," Soil Dynamics and Earthquake Engineering, vol. 126, p. 105813, 2019.

[22] C. H. Hu, System Analysis and Design Based on MATLAB: Wavelet Analysis, Xidian University Press, Warsaw, China, 1999.

[23] Y. P. Zou and X. Li, Signal Conversion and Processing, Huazhong University of Technology Press, Wuhan, city, 1993.

[24] S. W. Lu, Propagation Characteristics of Blasting Vibration in Slopes Subjected to Open-Pit to Underground Mining and Safety Criterion, China University of Geosciences, China, 2017.

[25] N. Jiang, C. Zhou, S. Lu, and Z. Zhang, "Propagation and prediction of blasting vibration on slope in an open pit during underground mining," Tunnelling and Underground Space Technology, vol. 70, pp. 409-421, 2017. 
[26] H. Tang, Experimental and Theoretical Study on Effect of Topography on Propagation of Blasting Waves, Graduate School of the Chinese Academy of Sciences(Wuhan Institute of Rock and Soil Mechanics), Wuhan, China, 2007.

[27] N. Jiang, B. Zhu, X. He, C. Zhou, X. Luo, and T. Wu, "Safety assessment of buried pressurized gas pipelines subject to blasting vibrations induced by metro foundation pit excavation," Tunnelling and Underground Space Technology, vol. 102, Article ID 103448, 2020.

[28] Z. C. Zhang, C. M. Lin, Z. B. Huang, and B. Y. Ge, "Prediction of blasting vibration of area near tunnel blasting source," Explosion and Shock Waves, vol. 34, no. 3, pp. 367-372, 2014. 